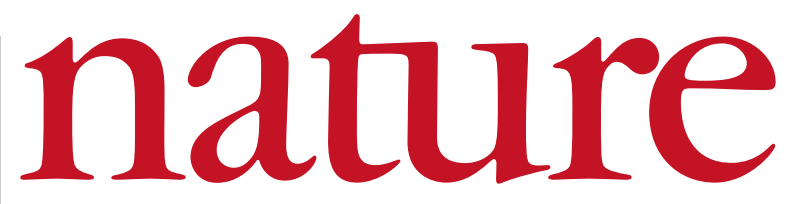

2 December 2004 Volume 432 Issue no 7017

\title{
The e-developing world
}

Participants in an international forum last month were appropriately fired up about the opportunities for the poorest countries that are provided by information technologies. The attitudes of governments can make all the difference.

$\mathrm{G}$ o up Hiei-zan, a mountain to the east of Kyoto, and you encounter a timeless, peaceful space: the vast Enryaku-ji temple complex, founded in the eighth century. Enter the most important building and you find, in the dimly lit and incenseladen atmosphere, statues of Buddha accompanied by flames kept burning for 1,200 years, with monks as guides and people kneeling in contemplation and prayer.

Look elsewhere in Kyoto and you will no doubt encounter a very different space: virtual rather than physical, and filled with continuously text-messaging teenagers who consider it impolite to take more than an hour to respond to a message on their mobile phones, even if they're in the middle of classes at school.

Participants at the Science and Technology in Society Forum, held last month in Kyoto (see www.stsforum.org), had a chance to see the former space and to discuss the development of the latter and other similar e-spaces. They heard about the growing ability of broadband mobile technologies to "put the world in your hand". They heard about the Grid, which takes gigantic computational or data tasks, breaks them down into streams of data packets, and distributes their processing around a vast computer network. This will give the fabric of the Internet the capacity not only to ingest terabytes of data in an hour or less, but also to compare the data with models, to seek patterns, and to test hypotheses in real time or even faster. This infrastructure is being developed with scientific and defence-related challenges very much in mind, but no doubt it will also contribute to the world in everybody's hand.

Except that it isn't everybody, of course. The people who stand to benefit most from these developments are the minority who live in the developed world. So how to enhance access for the rest? A discussion of "The e-developing world" focused on seeking solutions that were sustainable in a business sense. The participants included senior people from technology and telecommunications companies such as Sun Microsystems, Intel, Nokia and UTStarcom, as well as from universities and the US National Science Foundation. So, they were asked, is it realistic to expect that multinationals will target as a market the four billion people at the bottom of the human pyramid - the poorest on the planet — rather than just the billion at the top?

\section{Spreading the word}

Most of the participants were optimistic. After all, if a company has well established core markets, it can afford to go after other markets that build new revenues on marginal costs. There are already such companies, spurred on by business-positive governments in the emerging markets.

Two elements are essential. The first consists of imaginative ways of increasing the reach of the technology. The use of micro-enterprises is one example, such as the 'phone lady', a local village woman who sells minutes of Internet time. Governments can also play a role: for instance, the Kerala government in India is to provide some 7,000 villages with Internet cafés, each with ten computers, and will use them to deliver important services to the villages.

Another key element is micro-commerce. Information and communication technologies (ICT) can be used to reduce the cost of credit, cut costs by removing the middle-man, and hook major banks reliably to micro-credit.

Success breeds success, so it is worth considering some inspiring examples. Text messages using 'short message service' - the same technology used by Kyoto's teenagers - are used to alert people to take tuberculosis medicine in South Africa. More sophisticated telemedicine in remote regions also has high potential payoff. The UN World Food Programme uses high frequency, very low bandwidth to communicate with trucks in its distribution network. The propagation of instructional materials has been effective - in Togo, West Africa, for example, Internet cafés are just a bicycle ride away. And one of the most successful examples of the use of ICT in developing regions has been 'price discovery' - using the technology to discover the price of commodities (such as soy beans) in large markets and then negotiating appropriately with the 'middle-man'buyer.

\section{Political will}

To speak of the 'developing world' is overly simplistic: there is a vast difference between small developing countries and China or India. And the difference between these giants is itself instructive, most fundamentally in the role played by government - at national, state and local levels. In China, these governments see themselves as a kind of competitive business, and work hard and proactively to bring about the kind of infrastructure they would like to see in their country, state, region or village. India, in practice, despite its success in information-technology service development, is seen as less welcoming territory for outsiders with technology to offer.

Educating open-minded government officials in best practice in ICT can have huge leverage. If governments see themselves as groups to be wooed by business, they will lose out. They must be proactive and work in partnership with other agencies and companies to increase the size of the cost-effective, reachable market for goods and services. Over the next ten years, the biggest heroes in the deployment of ICT in the developing world will not be the engineers or the business leaders, but the most effective political leaders.

Perhaps the most stimulating task given to the discussion by its chairman Richard Newton, dean of engineering at the University of California, Berkeley, was to come up with a prize challenge: what technological achievements for the developing world would merit a US\$10-million award? Three ideas stood out: an affordable computerbased tutor that could instruct an illiterate person to learn a useful activity within a month; a phone that translates between languages in real time; and a demonstrable reduction by at least two orders of magnitude in the cost per bit of information delivery.

Whatever politicians and businesses might achieve, technologists should not lose sight of the need for simplicity. This is essential for illiterate people in remote villages in the poorest countries. It is also important for older people everywhere who want nothing to do with the Internet and yet could benefit so much from communicating more readily with their grandchildren.

For those who live in the e-developed world, the challenge is increasingly becoming how to switch off. Those lucky enough to visit Kyoto should start by visiting the temples on Hiei-zan. 